\title{
Human Papillomavirus and Cervical Intra-Epithelial Neoplasia: Epidemiological and Cytological Study in Lubumbashi Women
}

\author{
Mwenze Didier, ", Kyabu Véronique ${ }^{1}$, Mulenga Philippe ${ }^{2}$, Mukalay Abdon ${ }^{2}$, Chola Joseph $^{3}$, \\ Kalenga Prosper ${ }^{3}$, Ilunga Julien ${ }^{1}$ \\ ${ }^{1}$ Pathology Department, University of Lubumbashi, Lubumbashi, Democratic Republic of Congo \\ ${ }^{2}$ Public Health Department, University of Lubumbashi, Lubumbashi, Democratic Republic of Congo \\ ${ }^{3}$ Gynecology Obstetrics Department, University of Lubumbashi, Lubumbashi, Democratic Republic of Congo
}

Email address:

mwenze.mwadi@gmail.com (M. Didier)

${ }^{*}$ Corresponding author

\section{To cite this article:}

Mwenze Didier, Kyabu Véronique, Mulenga Philippe, Mukalay Abdon, Chola Joseph, Kalenga Prosper, Ilunga Julien. Human Papillomavirus and Cervical Intra-Epithelial Neoplasia: Epidemiological and Cytological Study in Lubumbashi Women. International Journal of Clinical Oncology and Cancer Research. Vol. 4, No. 1, 2019, pp. 1-4. doi: 10.11648/j.ijcocr.20190401.11

Received: March 28, 2019; Accepted: May 5, 2019; Published: May 30, 2019

\begin{abstract}
The objective of this study is to show that the presence of koilocytosis on the cervical smear is the only possibility to detect Papillomavirus infection in cervical intra-epithelial neoplasia in women living in Lubumbashi. This is a crosssectional analytical study on the data collected from the register of women who participated in the cervix lesion screening campaign organized in Lubumbashi in March 2012 by the Congolese League Against Cancer. A total of 545 women with cervical lesions have been selected. The following results were observed: the frequency of HPV infection is $35 \%$ in Lubumbashi women. The risk of developing intraepithelial neoplasia is 38.3 times higher in women infected with HPV compared to uninfected ones ( $\mathrm{OR}=38.3,95 \% \mathrm{CI}=16.3-90.3)$. HPV is predominantly present in intraepithelial neoplasia $(92.7 \%)$ and this regardless of their grade: $91.9 \%$ for low-grade neoplasia and $95 \%$ for high-grade neoplasia. HPV is found in both older women and older women, respectively in $45 \%$ of women aged less than 36 years and in $55 \%$ of women aged over 36 years old. This study shows that it is necessary to put in place adequate means for the detection of HPV in order to contribute to the fight against cervical cancer in Lubumbashi.
\end{abstract}

Keywords: Papillomavirus, Intra Epithelial Neoplasia, Cervix, Lubumbashi

\section{Introduction}

Papillomaviruses are a large family of small, nonenveloped DNA viruses with epithelial tropism and high resistance $[1,2]$. Their genome is a circular DNA molecule of about 8,000 nucleotide pairs. They have in common a genetic organization characterized by the presence of eight genes, encoding proteins involved in the interaction with the host cell (E genes) or coding for constituents of the viral capsid (L genes) [2]. These genes are located downstream from a noncoding region, containing sequences regulating the replication and transcription of the viral genome [2]. Human papillomavirus (HPV) genital infection has two diametrically opposite aspects, which are, on the one hand, the common sexually transmitted disease, very common, most often asymptomatic and transient, accompanied by acquired and effective immunity.; On the other hand, this infection is a disease inducing epithelial changes [3], which can lead to the development of cervical cancer and its precursor lesions as demonstrated by numerous clinical, epidemiological and molecular studies [4]. Women at risk for HPV infection are characterized by premature sexual life and multiple sexual partners or sexual promiscuity of their partner (s), suggesting the sexual transmission of a long-lasting [5]. This factor leads to cellular alteration in the form of koilocytosis, identifiable on cervical smears [2]. Koilocytosis are the stigma of papillomavirus replication in the cervix [6] and are frequently 
associated with intra-epithelial neoplasia. The frequency of this virus on cervical smears varies from 25 to $50 \%$ in women aged 15 to 25 who are sexually active [2]. This prevalence decreases with age and generally varies from 5 to $15 \%$ in women over 35 years of age [7]. The prevalence of HPV infection also remains high in elderly women; in certain populations [8]. There are several methods for identifying HPV on cervical lesions. [2]. It is particularly the HPV testing carried out with a commercial kit (Digene Cervical Sampler) including a cervical brush, the "Hybrid" test. Capture II "(HCII) (Digene, Gaithersburg, MD, USA) which is used to study high-risk HPV infection [9], and amplification of a short region of viral DNA by the technique of polymerase chain reaction (PCR). In Democratic Republic of Congo and more specifically in Lubumbashi for lack of adequate equipment, none of these methods are used. The only possibility of detecting HPV infection on cervical smears in this country is to proceed indirectly through microscopic research of koilocytosis (stigmas of papillomavirus replication). This study aims to show that the koilocytosis on the cervical smear is the only possibility for the detection of HPV in intra-epithelial neoplasia in Lubumbashi and also it aims to determine the frequency of HPV carriage in the population of Lubumbashi and analyze the relationship between HPV infection and cervical intraepithelial neoplasia.

\section{Method}

\subsection{Type of Study}

This is a cross-sectional analytical studybased on an analysis of cervical smear for the campaign of intra-epithelial neoplasia detection organized in March 2012 by the Congolese League against Cancer registry in Lubumbashi.

\subsection{Selection of Cases}

Before carrying out this study, we collected slides of cervical smear from 629 sexually active women living in Lubumbashi who voluntarily participated in the precancerous cervical lesions screening campaign organized in March 2012 by the Congolese League Against the cancer.

\subsection{Inclusion Criteria}

Women who participated in the campaign with an inflammatory smear or intra-epithelial neoplasia of the cervix according to the modified Bethesda classification were included in this study, resulting in a total of 545 cases.

\subsection{Exclusion Criteria}

Women whose smears were inadequate or within normal limits were excluded from this study, for a total of 84 women.

\subsection{Cytology Treatment}

The cervical smears were stained according to the conventional Harris-Shorr technique by following the following steps: Fixation in methanol for 15 minutes, passage in three diluted ethyl alcohol baths at $95^{\circ}, 70^{\circ}$, and $50^{\circ}$, rinsing with distilled water, staining with Harris hematoxylin for 5 minutes, rinsing with distilled water, passing through the bath of ammonia alcohol for 15 seconds, rinsing with water distilled, the successive passage in three baths of ethical alcohol diluted at $50^{\circ}, 70^{\circ}$ and $95^{\circ}$, the staining with Shorr for three minutes, the passage in two baths of alcohol of $95^{\circ}$ and $100^{\circ}$, the passage in two xylene baths and finally the break of covers object before microscopic analysis [10].

\subsection{Cytopathological Analysis}

The cytopathological analysis was performed at the Pathological Department of the University Hospitalof Lubumbashi independently by three experienced pathologists using the modified Bethesda classification [11]. In the event of a discrepant diagnosis between the three pathologists, a consensus should be found based on the documentation. Six classes were retained: (1) inadequate smear, (2) smear within normal limits, (3) cytology compatible with inflammatory changes (4) and epithelial neoplasia. This category had 2 subclasses: low grade and high grade intraepithelial neoplasia. The search for koïlocytosis (cells carrying a perinuclear halo) [12] was systematically made to the X40 objective on all cases of smear with inflammatory alterations and those with intra-epithelial neoplasia of the cervix.

\subsection{Parameters}

There is the age of women examined and the morphological aspects of cervical smears as well as the presence of koilocytosis.

\subsection{Statistical Analyzes}

Statistical analyzes were done on a Compaq CQ58 laptop. The Epi Info 2011 software was used for data processing. Proportions were calculated and expressed as a percentage. The exact Fisher test, the Chi-square test, the Odds ratio and the confidence interval were used for the comparison of proportions. The value of $\mathrm{p}<0.05$ was considered statistically significant.

\section{Results}

\subsection{Age of Women}

The average age of the 545 women in Lubumbashi selected in this study was $40 \pm 5.4$ years. The age limits ranged from 22 to 65 years old.

\subsection{Cytological Classification}

Intra-epithelial neoplasia of the cervix constituted $15 \%$ of cases $(\mathrm{n}=82)$, inflammatory lesions accounted for $85 \%$ of cases $(n=463)$. Table 1 illustrates these results. 
Table 1. Cytological evaluation of smears $(n=545)$.

\begin{tabular}{lll}
\hline Evaluation & Number & \% \\
\hline CIN & 82 & 15 \\
Inflammatory smears & 463 & 85 \\
Total & 545 & 100 \\
\hline
\end{tabular}

CIN (Cervical Intra-epithelial neoplasia).

\subsection{Association Between HPV and Intra-Epithelial Neoplasia}

Women with HPV stigma (koilocytosis) were 38.3 times more likely to develop intra-epithelial neoplasia compared to those who did not. This difference was statistically significant $\left(\mathrm{OR}=38.3,95 \% \mathrm{CI}=16.3-90.3, \chi^{2}=137.9, \mathrm{p}\right.$ $<0.0001)$. Table 2 reports these observations.

Table 2. Koilocytosis and cervical lesions $(n=545)$.

\begin{tabular}{llll}
\hline Koilocytosis & CI Nnumber (\%) & $\begin{array}{l}\text { Inflammatory smears } \\
\text { Number (\%) }\end{array}$ & Total \\
\hline Absent & $6(7.3 \%)$ & $348(75,2 \%)$ & 354 \\
Present & $76(92,7 \%)$ & $115(24,8 \%)$ & 191 \\
Total & 82 & 463 & 545 \\
\hline
\end{tabular}

$\mathrm{OR}=38,3 ;$ IC $95 \%=16,3-90,3 ; \chi^{2}=137,9 ; \mathrm{p}<0,001$.

\subsection{Koilocytosis and Patient Ages}

The distribution of women with koilocytosis shows that 55\% of women $(n=105)$ with koilocytosis were older to 35 years while the remaining $45 \%(\mathrm{n}=86)$ were aged at under 35 (Table 3).

Table 3. Age of women and koilocytosis $(n=191)$.

\begin{tabular}{lll}
\hline Age & Fréquency of koilocytosis & $\%$ \\
\hline$\leq 35$ years & 86 & 45 \\
$\geq 36$ years & 105 & 55 \\
Total & 191 & 100 \\
\hline
\end{tabular}

\subsection{Correlation Between Koilocytosis and CIN Grade}

Koilocytosis were found in $91.9 \%(n=57)$ of low-grade precancerous lesions and $95 \%(\mathrm{n}=19)$ of precancerous highgrade lesions, respectively. This difference was not statistically significant $(\mathrm{OR}=1.7,95 \% \mathrm{CI}=0.2-15.2$, exact Fisher, $\mathrm{p}=1$ ) (Table 4).

Table 4. Correlation between CIN grade and koilocytosis $(n=82)$.

\begin{tabular}{lll}
\hline Koilocytosis & $\begin{array}{l}\text { High grade CI } \\
\text { Nnumber and }(\%)\end{array}$ & $\begin{array}{l}\text { Low grade CI Nnumber } \\
\text { and }(\%)\end{array}$ \\
\hline Absent & $1(5 \%)$ & $5(8,1)$ \\
Présent & $19(95)$ & $57(91,9)$ \\
Total & 20 & 62 \\
\hline
\end{tabular}

$\mathrm{OR}=1,7 ; \mathrm{IC} 95 \%=0,2-15,2 ;$ Fisher exact; $\mathrm{p}=1$.

\section{Discussion}

\subsection{HPV Detection Methods}

There are several methods for detecting and identifying HPV in cell harvesting. The most sensitive is based on the amplification of a short region of viral DNA by the polymerase chain reaction (PCR) technique and the use of degenerate primers or consensus primers, localized in the L1 gene, which amplifies a broad spectrum of HPV genotypes with genital tropism [2]. This technique is widely used in the detection and identification of HPV infections [13-15]. Other tests are based on the detection of viral DNA by molecular hybridization, without prior amplification; their sensitivities are lower than those based on PCR or the hybrid capture technique [2]. The Hybrid test is also used [16] and can detect a potentially oncogenic HPV (or a non-oncogenic HPV), but without identifying the genotype involved [9]. For lack of adequate equipment, all these techniques are not used in Lubumbashi, the only possibility to detect HPV indirectly in this city is to identify the koilocytosis in cervical smears. This cytologic abnormality is frequently associated with intra-epithelial neoplasia, and represents the stigma of papillomavirus replication in the [6].

\subsection{Age of Women}

The mean age of women in the present study is $40 \pm 5.4$ years and the range is 22 to 65 years. Boumba et al., found an average age of $43.6 \pm 9.5$ years (range 16 to 72 years) in a population of Brazzaville [17]. These observations show that these two populations live in the same socio-demographic conditions.

\subsection{Frequency of HPV Infection in the Population}

The frequency of HPV infection in Lubumbashiis 35\% in this study. Boulanger et al., found a frequency of HPV carriage of $14.32 \%$ in the French population [16]. Boumba et al. found a frequency of $23.5 \%$ HPVin the Congolese population (Brazzaville) [1]. The sensibility and the specificity of the techniques used for the identification of HPV explainthese differences of frequency.

\subsection{HPV and Intra-Epithelial Neoplasia of the Cervix}

The stigmata of HPV were found in $92.7 \%$ of cases of intra-epithelial neoplasia in this study. Boumba et al had observed HPV infection in $89.6 \%$ of cases of intra-epithelial neoplasia [17]. Many studies demonstrate a high frequency of human papillomavirus (HPV) infection in intra-epithelial neoplasia [18].

\subsection{HPV and Grade of Cervical Intra-Epithelial Neoplasia}

HPV stigmata were found in $91.9 \%$ of cases of low-grade intraepithelial neoplasia and in $95 \%$ of those of high grade in this study, and this difference was not statistically significant. Boumba et al., showed that HPV infection was $80.9 \%$ lowgrade neoplasia and all high-grade neoplasms were HPVpositive [17]. These observations show that HPV infection was predominantly found in both low-grade and high-grade neoplasia.

\subsection{HPV Risk Factor for Intra-Epithelial Neoplasia}

This study shows that women with HPV stigmas were 38.3 
times more likely to develop cervical intra-epithelial neoplasia compared to those without HPV stigma. Kousky et al., reported that the risk of cervical intra-epithelial neoplasia was 11 times more in women with HPV infection than in women without HPV [19].

\subsection{HPV Stigmas and Patient Age}

The stigma of HPV is found in 55\% of women aged 36 years and over and $45 \%$ of those aged 35 and under in this study. According to observations made by Boumba et al, although they noted a $32 \%$ incidence of HPV infection in women under 30 , the difference in HPV frequency by age group was not statistically significant [1]. Young women are more affected by HPV infection, older women are also infected with this virus [21].

\section{Conclusion}

The stigmata of HPV are found in a not insignificant proportion in the women of Lubumbashi having sexual activity regardless of their age. These stigmas are strongly associated with intra-epithelial neoplasia of any grade. It is therefore important to put in place the most sensitive means of detecting HPV in order to contribute to the fight against cancer of the cervix in Lubumbashi.

\section{References}

[1] Boumba LMA, Mouallif M, Hilali L, Moukassa D, Ennaji MM. Prevalence of Human Papillomavirus infection among Congolese Women with Normal Cervical Cytology. IJSR. 2015; 4: 2319-7064.

[2] Orth G. Les papillomavirus humains et leur rôle dans l'histoire naturelle du cancer du col de l'utérus. Perspectives dans le domaine de la prévention de ce cancer. Dépist Cancer Col L'utérus. 2005; 15-33.

[3] Riethmuller D, Schaal JP, Mougin C. Épidémiologie et histoire naturelle de l'infection génitale à papillomavirus humain. Gynécologie Obstétrique Fertil. 2002; 30 (2): 139146.

[4] Zur Hausen H. Papillomaviruses and cancer: from basic studies to clinical application. Nat Rev Cancer. 2002; 2 (5): 342 .

[5] Rotkin ID. A comparison review of key epidemiological studies in cervical cancer related to current searches for transmissible agents. Cancer Res. 1973; 33 (6): 1353-1367.

[6] Meisels A, Morin C. Human papillomavirus and cancer of the uterine cervix. Gynecol Oncol. 1981; 12 (2): S111-S123.

[7] Baseman JG, Koutsky LA. The epidemiology of human papillomavirus infections. J ClinVirol. 2005; 32: 16-24.

[8] Castle PE, Schiffman M, Herrero R, Hildesheim A, Rodriguez $\mathrm{AC}$, Bratti MC, et al. A prospective study of age trends in cervical human papillomavirus acquisition and persistence in Guanacaste, Costa Rica. J Infect Dis. 2005; 191 (11): 18081816.
[9] Sankaranarayanan R, Nene BM, Dinshaw KA, Mahe C, Jayant K, Shastri SS, et al. A cluster randomized controlled trial of visual, cytology and human papillomavirus screening for cancer of the cervix in rural India. Int J Cancer. 2005; 116 (4): 617-623.

[10] Pundel JP, Lichtfus C. Modifications de la coloration cytologique des frottis vaginaux à l'hématoxyline-Shorr. Gynecol Obstet Invest. 1957; 144 (Suppl. 1): 58-60.

[11] Bergeron C, Cartier I, Guldner L, Lassalle M, Savignoni A, Asselain B. Lésions précancéreuses et cancers du col de l'utérus diagnostiqués par le frottis cervical, Ile-de-France, enquête Crisap, 2002. Bull Epidemiol Hebd. 2005; 2: 5-6.

[12] Lakmichi MA, Dahami Z, Elhaous A, Gabsi M, Boukhari M, Chekkal A, et al. Transformation spino-cellulaire de deux tumeurs de Buschke-Löwenstein. Afr J Urol. 2005; 11 (3): 225-229.

[13] Walboomers JMM, Jacobs MV, Van Oostveen JW, Van den Brule AJC, Snijders PJF, Meijer C. Detection of human papillomavirus infections and possible clinical implications. Hum Papillomavirus Infect Dermatovenereology Eds G Gross G Von Krogh CRC Press Lond Tokyo N Y. 1997; 341: 64.

[14] Lazar JG, Cullen AP, Mielzynska I, Meijide MG, Lorincz AT. Hybrid Capture (R): A sensitive signal amplification-based chemiluminescent test for the detection and quantitation of human viral and bacterial pathogens. J Clin Ligand Assay. 1999; 22 (2): 139-151.

[15] Chaudhary AK, Pandya S, Mehrotra R, Bharti AC, Singh M, Singh M. Comparative study between the Hybrid Capture II test and PCR based assay for the detection of human papillomavirus DNA in oral submucous fibrosis and oral squamous cell carcinoma. Virol J. 2010; 7 (1): 253.

[16] Boulanger J-C, Sevestre H, Bauville E, Ghighi C, Harlicot J-P, Gondry J. Épidémiologie de l'infection à HPV. Gynécologie Obstétrique Fertil. 2004; 32 (3): 218-223.

[17] Boumba LMA, Qmichou Z, Mouallif M, Attaleb M, Mzibri ME, Hilali L, et al. Human papillomavirus genotypes distribution by cervical cytologic status among women attending the General Hospital of Loandjili, Pointe-Noire, Southwest Congo (Brazzaville). J Med Virol. 2015; 87 (10): 1769-1776.

[18] Zur Hausen H. Papillomaviruses and cancer: from basic studies to clinical application. Nat Rev Cancer. 2002; 2 (5): 342 .

[19] Koutsky LA, Holmes KK, Critchlow CW, Stevens CE, Paavonen J, Beckmann AM, et al. A cohort study of the risk of cervical intraepithelial neoplasia grade 2 or 3 in relation to papillomavirus infection. N Engl J Med. 1992; 327 (18): $1272-1278$.

[20] Kinney W, Sung H-Y, Kearney KA, Miller M, Sawaya G, Hiatt RA. Missed opportunities for cervical cancer screening of HMO members developing invasive cervical cancer (ICC). Gynecol Oncol. 1998; 71 (3): 428-430.

[21] De Sanjosé S, Diaz M, Castellsagué X, Clifford G, Bruni L, Muñoz N, et al. Worldwide prevalence and genotype distribution of cervical human papillomavirus DNA in women with normal cytology: a meta-analysis. Lancet Infect Dis. 2007; 7 (7): 453-459. 